\title{
Al-Assisted Photochemical Etching of a-SiC Thin Films for $\mathrm{NH}_{3}$ Sensor
}

\author{
A. Boukezzata*, H. Menari and S. KaCi \\ Centre de Recherche en Technologie des Semi-conducteurs pour l'Energétique (CRTSE), \\ Division Couches Minces Surfaces et Interfaces (CMSI), Algiers, Algeria
}

\begin{abstract}
In this work, we present the formation of porous amorphous silicon carbide (PASiC) fabricated on a thin amorphous silicon carbide (a-SiC) film. The film was deposited on $p$-type silicon substrate $(\mathrm{a}-\mathrm{SiC} / \mathrm{Si}(p))$ by cosputtering DC magnetron using a single crystal Si target rand deposited onto 86 sprigs of hot pressed polycrystalline $6 \mathrm{H}-\mathrm{SiC}$. The thickness of the elaborated a-SiC films was $0.2 \mu \mathrm{m}$. Due to its high electrical resistivity of a-SiC:H thin film (higher than $2 \mathrm{M} \Omega \mathrm{cm}$ ), and in order to facilitate the chemical etching, a thin metallic film of high purity aluminum ( $\mathrm{Al}$ ), was deposited under vacuum. The PASiC films were made by Al-assisted photochemical etching using $\mathrm{HF} / \mathrm{AgNO}_{3}$ solution under UV illumination at $\lambda=254 \mathrm{~nm}$ with different etching times. The results show that the sample surface is uniformly covered with pores. The diameter of pores varied between 150 and $700 \mathrm{~nm}$. The optimum etching time corresponded to $30 \mathrm{~s}$ that exhibited a high PL intensity. The $\mathrm{NH}_{3}$ sensors were fabricated by evaporating coplanar interdigital gold $(\mathrm{Au})$ electrodes on PASiC and the vapor sensing properties were tested. Finally, the sensing performances are attributed to the unique surface structure, morphology of the pore and its size, which provide an effective pathway for vapor adsorption and enlarge the sensing area of Au-PASiC.
\end{abstract}

DOI: 10.12693/APhysPolA.137.454

PACS/topics: amorphous silicon carbide, porous SiC, metal-assisted, photochemical etching

\section{Introduction}

Silicon carbide, a wide band gap semiconductor, is believed to be the ideal material for the fabrication of electronic devices that can operate at higher power levels and operating temperatures than devices produced from Si. Not only does silicon carbide display superior electrical and mechanical properties but processing technologies using silicon carbide are compatible to silicon microfabrication technology. Also, silicon carbide has many advantages compared with silicon for micro-electro-mechanical systems (MEMS) [1-3], such as its high toughness, and its capability to work at high temperature and harsh environment. However, porous silicon carbide (PSC) has been found to be an interesting object for developing new technologies and applications for a number of years now. It is a potentially attractive material for fabricating ultraviolet light emitting diodes, efficient ultraviolet photodetectors, and chemical or physical sensors [4-7]. Also, it is a novel substrate for epitaxial film growth [8,9]. One major reason for some of these interests is that PSC has higher photoluminescence emission efficiency than bulk $\mathrm{SiC}$. There have been a large number of reports on PSC, which exhibits a variety of porous structures produced under various chemical etching conditions. Detection of ammonia $\left(\mathrm{NH}_{3}\right)$ is required in many applications including leak-detection in air-conditioning systems [10], sensing of trace amounts ambient $\mathrm{NH}_{3}$ in air for environmental analysis [11], breath analysis for medical diagnoses [12], animal housing [11], etc. Generally, because

*corresponding author; e-mail: boukezzataassia@crtse.dz it is toxic, it is required to be able to sense low levels $(\approx \mathrm{ppm})$ of $\mathrm{NH}_{3}$, but it should also be sensitive to much higher levels. $\mathrm{NH}_{3}$ gas is very corrosive, often causing existing $\mathrm{NH}_{3}$ sensors to suffer from drift and have short lifetimes. SiC with its well-known ability to withstand harsh chemical environments, should in principle be a better material for sensors in such environments. Membrane or thin film structures have also been demonstrated, which is a big advantage regarding ease of integration with standard processing due to greater flexibility in choice of doping type and concentration. We found porous $\mathrm{SiC}$, when used as the dielectric in a capacitive sensing arrangement, to be extremely sensitive to the presence of $\mathrm{NH}_{3}$ gas. Compared to existing FET $\mathrm{NH}_{3}$ sensors [13], our devices are a lot simpler to fabricate and achieve similar sensitivities.

In this work, we have investigated the effect of metalassisted electroless etching parameters in chemical solutions containing $\mathrm{HF} / \mathrm{AgNO}_{3}$. Scanning electron microscopy shows that the porous a-SiC (PASiC) is formed at Al-assisted photochemical etching method. In addition, we have made sensors of $\mathrm{NH}_{3}$ using porous PASiC. $\mathrm{NH}_{3}$ sensors were fabricated by evaporating coplanar interdigital gold electrodes on PASiC and these sensors were tested for adsorption and desorption of $\mathrm{NH}_{3}$ vapor.

\section{Experimental details}

Porous amorphous silicon carbide (PASiC) was fabricated using the thin amorphous a-SiC films. They were deposited on $p$-type silicon substrate (a-SiC $/ p$-Si $(100)$ by co-sputtering DC magnetron using a single crystal Si target deposited onto 86 hot pressed polycrystalline $6 \mathrm{H}-\mathrm{SiC}$ slices of $10 \mathrm{~mm} \times 5 \mathrm{~mm}$. The thickness of the 
films was $\approx 2000 \AA$. Two types of samples were prepared. In the first set, because of the high electrical resistivity of the thin a-SiC:H film around $2 \mathrm{M} \Omega \mathrm{cm}$, and in order to facilitate the chemical etching, a thin metallic film of high purity aluminum $(\mathrm{Al})$ was deposited under vacuum onto the thin a-SiC: $\mathrm{H}$ layer for reinforced solution etching. In the second set, samples were subjected to the one-step $\mathrm{Al}$-assisted electroless chemical etching in $1 \mathrm{HF}(25 \%) / 1 \mathrm{AgNO}_{3}(0.05 \mathrm{M})$ solution under UV illumination at $254 \mathrm{~nm}$ wavelength for different etching times varying from 5 to $90 \mathrm{~min}$. After the etching, the samples were found to be covered with a thick Ag layer, which was removed by immersion into aqueous $\mathrm{HNO}_{3}$ solution for 3 min. Samples were rinsed with deionized water $\mathrm{H}_{2} \mathrm{O}$ and dried with nitrogen $\mathrm{N}_{2}$ gas. The properties of a-SiC:H layer etched were investigated by scanning electronic microscopy (SEM), the Fourier transform infrared spectroscopy (FTIR), and photoluminescence spectrometry (PL). The $\mathrm{NH}_{3}$ sensors were fabricated by evaporating coplanar interdigital gold electrodes on PASiC and the vapor sensing properties were tested and carried out at atmospheric pressure and room temperature. The sensing principle of a $\mathrm{NH}_{3}$ sensor is based on the variation of current density of a sensor's surface caused by the $\mathrm{NH}_{3}$ vapor adsorption and desorption.

\section{Results and discussions}

\subsection{Macrostructure of PASiC}

The first stages of the etching were investigated by SEM. Plan view of the PASiC surface at different etching times are shown in Fig. 1. The sample surface is uniformly covered with pores. The diameter of pores, which is close to the surface of the sample, varies between 150 and $700 \mathrm{~nm}$.

\subsection{Infrared spectroscopy (FTIR)}

The study of the surface of the amorphous thin a$\mathrm{Si}_{0.70} \mathrm{C}_{0.30}: \mathrm{H}$ films, which were treated in a solution $1 \mathrm{HF}(25 \%) / 1 \mathrm{AgNO}_{3}(0.05 \mathrm{M})$ for different etching times by infrared spectroscopy, revealed that the intensity of the peak located at $766 \mathrm{~cm}^{-1}$ [14] corresponds to $\mathrm{Si}-\mathrm{C}$ vibration band decreases when the chemical etching time increases (Fig. 2). The growth is less after the chemical treatment, which indicates that the $\mathrm{Si}-\mathrm{C}$ bond is broken to form the oxide of silicon on the surface. The absorption band which is observed at 619 and $2088 \mathrm{~cm}^{-1}$ [15] is attributed to $\mathrm{Si}-\mathrm{H}_{2}$ and $\mathrm{Si}-\mathrm{Hn}$ peaks. The band centred at $97 \mathrm{~cm}^{-1}$ is assigned to the absorption pattern that marks the stretching vibration of the $\mathrm{Si}^{-} \mathrm{O}_{2}$ bond $[16,17]$, as well as to the interstitial oxygen which dissolves itself in the substrate $\mathrm{Si}$. Consequently, it shows that the $\mathrm{SiC}$ dissolution goes to the formation of an oxide on the surface. This study revealed also the presence of a band at $2343-2373 \mathrm{~cm}^{-1}$ which can be assigned to $\mathrm{CO}_{2}$ stretching band (Fig. 2).
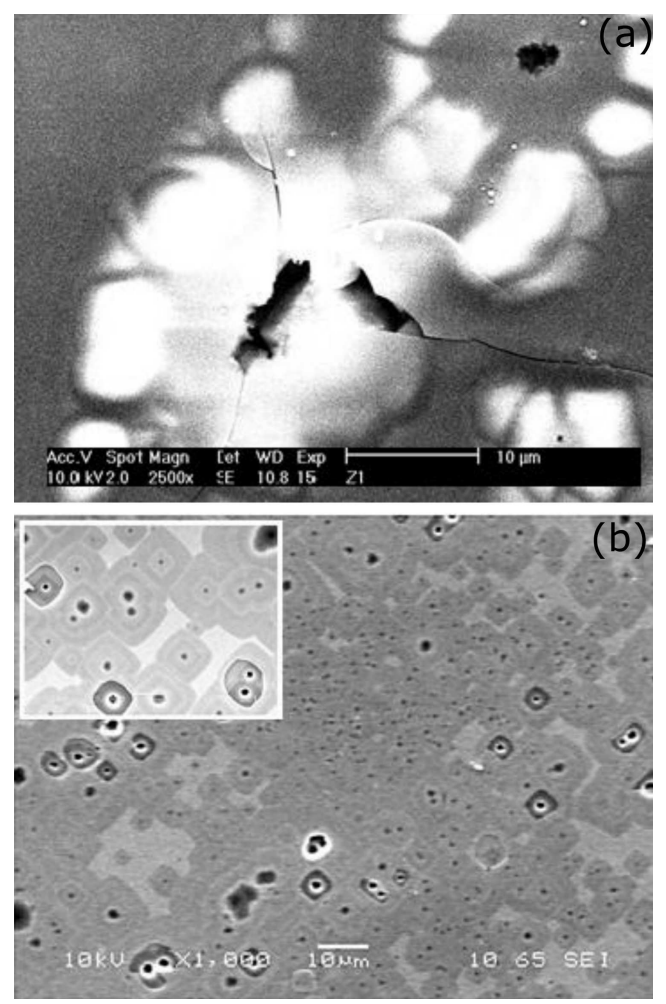

Fig. 1. Plan view SEM images of $\mathrm{Al} / \mathrm{a}-\mathrm{SiC}: \mathrm{H} / \mathrm{Si}$ thin films etched in $1 \mathrm{HF}(25 \%) / 1 \mathrm{AgNO}_{3}(0.05 \mathrm{M})$ solution for $t=30 \mathrm{~min}$ (a), and $t=60 \mathrm{~min}(\mathrm{~b})$.

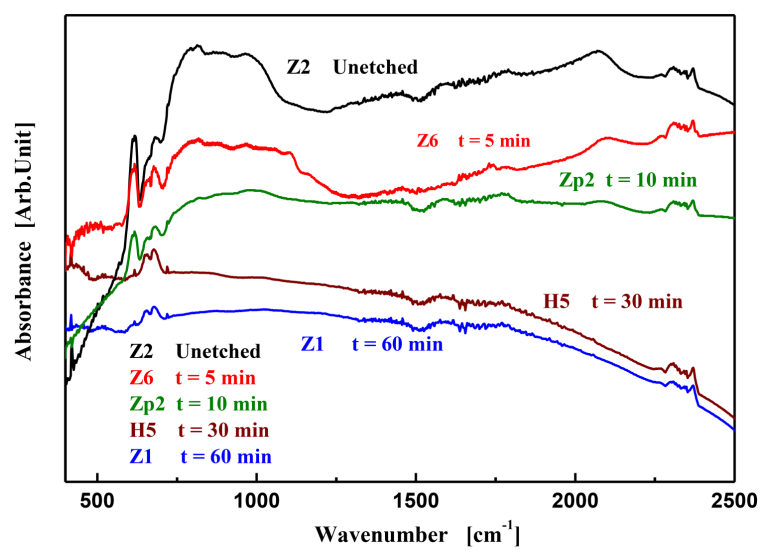

Fig. 2. FTIR spectrum of $\mathrm{Al} / \mathrm{a}-\mathrm{SiC}: \mathrm{H} / \mathrm{Si}$ thin films etched in $1 \mathrm{HF}(25 \%) / 1 \mathrm{AgNO}_{3}(0.05 \mathrm{M})$ solution for different etching time.

\subsection{Photoluminescence measurements}

Figure 3 shows PL spectra of amorphous thin a-SiC:H films before and after photochemical treatment in a solution of $1 \mathrm{HF}(25 \%) / 1 \mathrm{AgNO}_{3}(0.05 \mathrm{M})$ for different etching times ranging from 5 to $60 \mathrm{~min}$. The PL spectra exhibit two bands, a blue one with two peaks at $385 \mathrm{~nm}$ $(3.22 \mathrm{eV})$ and $450 \mathrm{~nm}(2.75 \mathrm{eV})$ and a green band centered at $520 \mathrm{~nm}(2.38 \mathrm{eV})$. The sample etched for $30 \mathrm{~min}$ 


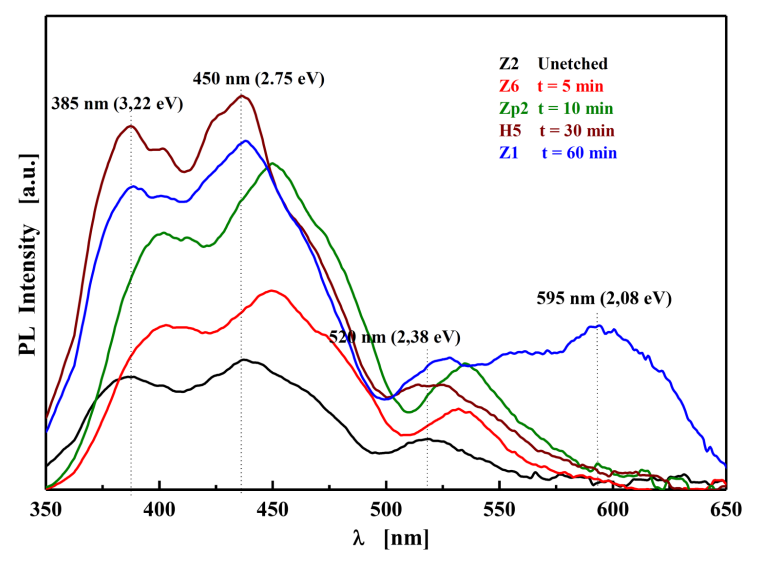

Fig. 3. Pholuminescence spectra of a-SiC:H films before and after etching in $1 \mathrm{HF}(25 \%) / 1 \mathrm{AgNO}_{3}(0.05 \mathrm{M})$ solution at different etching times.

exhibits a high PL intensity compared to the unetched sample. After increasing the etching time above $60 \mathrm{~min}$, where the luminescence measurement exhibited both previous band and a red band centred at $595 \mathrm{~nm}(2.08 \mathrm{eV})$, this later band was due to etched silicon and the optimum etching time corresponds to $30 \mathrm{~min}$ (Fig. 3). This time indicates that the PL intensity of the blue band is more important and decreases when the etching time increases. Wang et al. found that the PL intensities are enhanced by UV irradiation $325 \mathrm{~nm}$ at room temperature and the luminescence center with peak energy $2.3 \mathrm{eV}$ is induced by the UV light for the porous-like $\mathrm{SiC}$ samples. They suggested that UV irradiation may induce metastable states as luminescence centers in the sample $[18,19]$. We observe that the photoluminescence (PL) spectrum of the etched thin $\mathrm{SiC}$ layer exhibits much more intense visible luminescence at room temperature than that of the non-etched sample. There are several reports in the literature that report an increase in photoluminescence intensity in the $2.47-3.3 \mathrm{eV}$ region of the spectrum upon the formation of PSC [20]. Note that the luminescence intensity varies inversely with the pore diameter and the time of porosification corresponding to macroporous structure has been found to be $5 \mathrm{~min}$.

\subsection{Au-PASiC/p-Si(100) $\mathrm{NH}_{3}$ sensors}

The $\mathrm{NH}_{3}$ vapor sensor was constructed by evaporating coplanar interdigital gold electrodes onto surface of PA$\mathrm{SiC}$ under a vacuum thermal evaporation method. The schematic diagram of electrode arrangement on the surface of PASiC sensor is shown in Fig. 4.

\subsection{Device responses of sensors}

Figure 5 indicates clearly the role of porous structure $\mathrm{SiC}$ on the electrical properties of the sensor in presence of hydrogen nitride vapor $\mathrm{NH}_{3}$. The values of electrical parameters determined in different ambient (air ambient and $\mathrm{NH} 3$ vapor) are found to be dependent on the $\mathrm{SiC}$

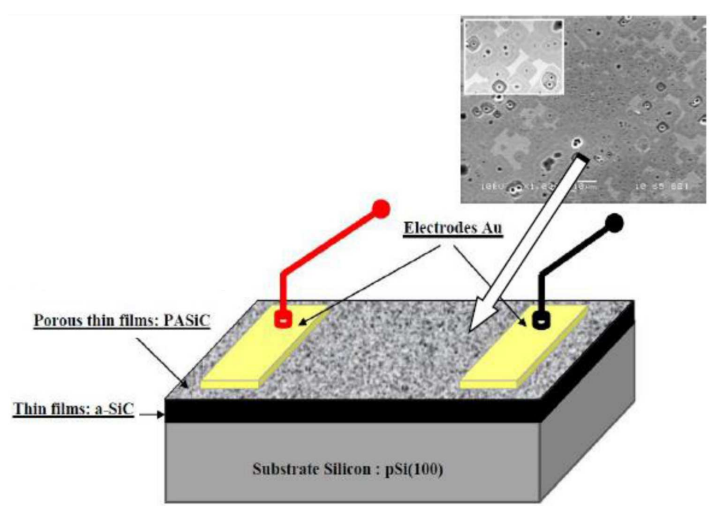

Fig. 4. A schematic of the devices used in this work. The sensing mechanism with porous $\mathrm{SiC}$ as sensing dielectric.
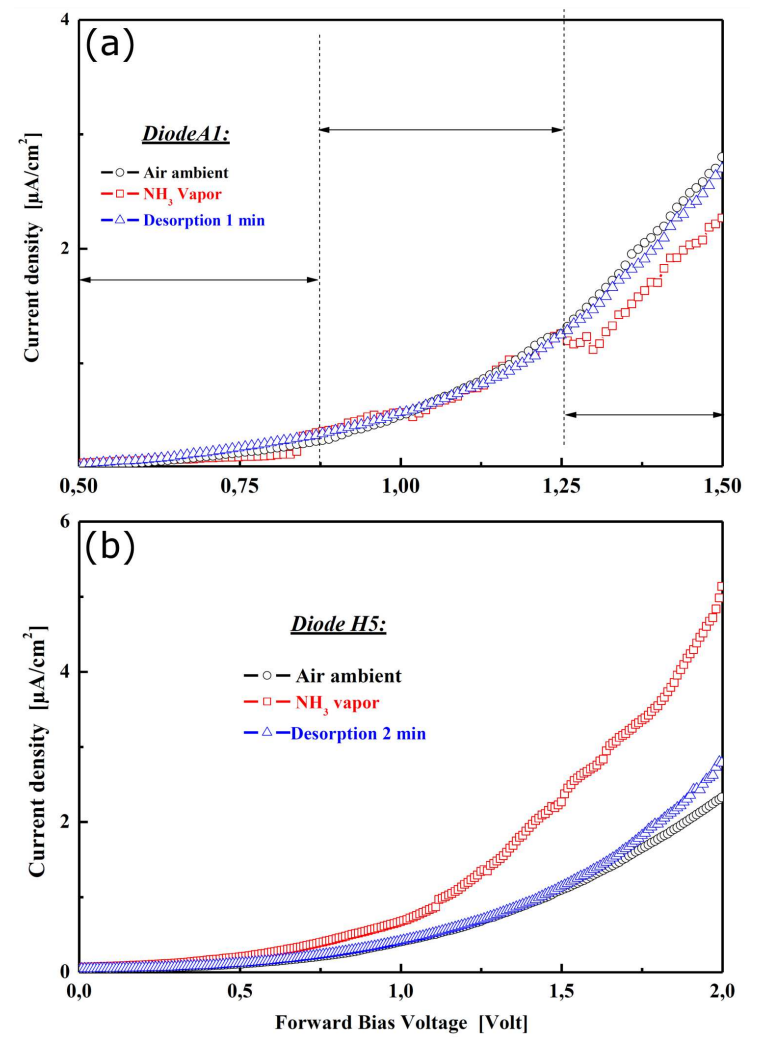

Fig. 5. Current-voltage characteristics of $\mathrm{NH}_{3}$ vapor sensor: (a) $\mathrm{Au} / \mathrm{a}-\mathrm{SiC} / \mathrm{Si}$ sensor, (b) $\mathrm{Au} / \mathrm{PASiC} / \mathrm{Si}$ sensor.

structures and the nature of ambient vapor, shown in Fig. 5ab. Finally, the maximum sensitivity of the structure $\mathrm{Au} / \mathrm{PASiC}$ is reached at low bias voltage $(0.5 \mathrm{~V})$ in presence of vapors (Fig. 5b).

However, we noted that the performance of the sensor depends strongly on the quality of the metalsemiconductor interface which is significantly influenced by the sample morphology, sponginess, and macroporosity of the semiconductor. 


\subsection{Response and recovery time}

Figure 6 depicts the response/recovery curves of $\mathrm{Au}-$ $\mathrm{PASiC} / p$-Si(100) structure for adsorption and desorption of $\mathrm{NH}_{3}$ vapor. As it can be seen, the calculated response and recovery times are found to be about $76 \mathrm{~s}$ and $84 \mathrm{~s}$, respectively. Moreover, the response and recovery time are relatively equal and longer than those of sensors based on traditional porous silicon (PSi) [21].

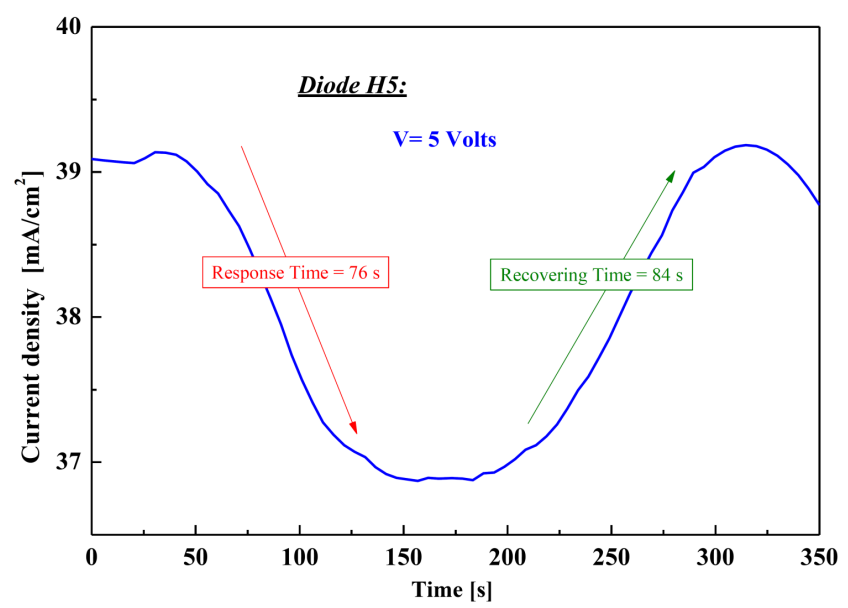

Fig. 6. Response/recovery time characteristics of $\mathrm{NH}_{3}$ vapor sensor.

\section{Conclusion}

Macrocomposite PASiC films were prepared by growing a-Si $\mathrm{S}_{0.70} \mathrm{C}_{0.30}: \mathrm{H}$ on $p$-Si(100) using co-sputtering $\mathrm{DC}$ magnetron process. These thins films were treated by photochemical etching and the average diameters of the pores were evaluated to be $150 \mathrm{~nm}$. The PL intensity indicates that the optimum etching time corresponds to $30 \mathrm{~min}$. On the sample surface, by evaporating coplanar interdigital gold electrodes, the room-temperature $\mathrm{NH}_{3}$ vapor sensing properties of PASiC were studied. We noticed that the resistance of $\mathrm{Au}-\mathrm{PASiC}$ highly increases compared to unetched $\mathrm{Au}-\mathrm{a}-\mathrm{SiC}: \mathrm{H}$ films. Moreover, it has been shown that the measured resistance of the structure highly depends on the applied bias voltage. Finally, our results indicate that $\mathrm{PASiC}$ might be a promising $\mathrm{NH}_{3}$ vapor sensing material for practical application.

\section{Acknowledgments}

This work was supported by Funds National Research (DG-RSDT/MESRS, Algeria).

\section{References}

[1] G. Müller, G. Krötz, E. Niemann, Sens. Actuat. A 43, (1994).

[2] M. Mehregany, C.A. Zorman, Thin Solid Films 518, 355 (1999).

[3] P.M. Sarro, Sens. Actuat. A 82, 210 (2000).

[4] H. Mimura, T. Matsumoto, Y. Kanemitsu, Appl. Phys. Lett. 65, 3350 (1994).

[5] J. Gao, T. Gao, M.J. Sailor, Appl. Phys. Lett. 77, 901 (2000).

[6] M. Ben-Chorin, A. Kux, I. Schechtger, Appl. Phys. Lett. 64, 481 (1994).

[7] S. Zangooie, R. Bjorklund, H. Arwin, Sens. Actuat. B 43, 168 (1997).

[8] N. Kuznetsov, K. Mynbaev, V. Dmitriev, Appl. Phys. Lett. 78, 117 (2001).

[9] J.E. Sapnier, G.T. Dunne, L.B. Rowland, I.P. Herman, Appl. Phys. Lett. 76, 3879 (2000).

[10] International Institute of Ammonia Refrigeration.

[11] T.T. Groot, Sense of Contact 6, keynote: Sensor Research at Energy Research Center, Netherlands (ECN), 2004.

[12] B.H. Timmer, Ph.D. Thesis, U. Twente, The Netherlands 2004.

[13] A. Lloyd Spetz, in: Proc. TAFT'2000, Nancy (France), 2000.

[14] K. Bourenane, A. Keffous, G. Nezzal, A. Boukezzata, S. Naama, Surf. Interface Anal. 39, 392 (2007).

[15] H. Minura, T. Matsumoto, Y. Kanemitsu, J. NonCryst. Solids 198, 961 (1996)

[16] A.V. Vasin, Sh. Muto, Yu. Ishikawa, A.V. Rusavsky, T. Kimura, V.S. Lysenko, A.N. Nazarov, Thin Solid Films 519, 2218 (2011).

[17] Y.H. Seo, H.J. Lee, H.I. Jeon, D.H. Oh, K.S. Nahm, Y.H. Lee, S.J. Suh, Y.G. Kwang, Appl. Phys. Lett. 62, 1812 (1993).

[18] J.N. Wang, Z.M. Chen, P.W. Woo, W.K. Ge, Y.Q. Wang, M.B. Yu, Appl. Phys. Lett. 74, 923 (1999).

[19] S. Kin, J.E. Spanier, I.P. Herman, Jpn. J. Appl. Phys. 39, 5875 (2000).

[20] J. Xu, J. Mei, Y. Rui, D. Chen, Z. Cen, W. Li, J. NonCryst. Solids 352, 1398 (2006).

[21] E.J. Connolly, H.T.M. Pham, J. Groeneweg, P.M. Sarro, P.J. French, Sens. Actuat. B 100, 216 (2004). 